\title{
UM OLHAR SOBRE A INFÂNCIA E AS BRINCADEIRAS INFANTIS A PARTIR DE RELATO DE IDOSOS DA CIDADE DE MINEIROS
}

\section{A LOOK AT CHILDHOOD AND CHILDREN'S PLAY FROM THE REPORTS OF THE ELDERLY OF THE CITY OF MINEIROS}

\section{UNA MIRADA A LA INFANCIA Y LOS JUEGOS INFANTILES A PARTIR DEL RELATO DE ADULTOS MAYORES DE LA CIUDAD DE MINEIROS}

Luciene Aparecida Pinto Costa Pereira*

\begin{abstract}
Resumo: O presente trabalho: "Um olhar sobre a infância e as brincadeiras infantis a partir de relatos de idosos da cidade de Mineiros", é resultado do processo de pesquisa desenvolvido no período de 2004 a 2007. O trabalho teve como objetivo conhecer e compreender as brincadeiras infantis na vida dos idosos de Mineiros nas décadas de 1910 a 1940 . Propusemos investigar sobre qual o lugar das brincadeiras na infância dos idosos de Mineiros e, para tanto, buscamos articular os elementos históricos constitutivos da infância principalmente em Goiás. A pesquisa teve como orientação teórica o materialismo-histórico-dialético e o método utilizado foi o qualitativo do tipo histórico. Como instrumentos consultamos documentos, leituras bibliográficas, depoimentos, relatos orais e entrevistas, como forma de obter informações e conhecimentos a respeito do objeto investigado. O universo da pesquisa abrangeu um número de 180 entrevistados, sendo 97 homens e 83 mulheres com idades que variavam entre 61 a 103 anos. Procuramos, por meio dos relatos e entrevistas dos idosos, fazer um levantamento das brincadeiras vivenciadas por eles durante a infância e que permanecem no universo infantil. Dentre as mais citadas encontramos as brincadeiras de roda, de curralzinho, de cavalinho de pau, de casinha e de laçar bezerro. Também discutimos algumas categorias que emergiram a partir dos relatos dos idosos, como trabalho, violência e gênero.
\end{abstract}

Palavras-chave: Infância. Brincadeira de criança. Idoso. Memórias.

\begin{abstract}
The present work: “A look at childhood and children's play from the reports of the elderly of the city of Mineiros”, is the result of the research process developed from 2004 to 2007. The objective of this work was to know and understand the role of children's games in the life of the elderly of Mineiros in the decades of 1910 to 1940 . We proposed to investigate what is the place of plays in the childhood of the elderly of Mineiros and, for that, we seek to articulate the historical constitutive elements of childhood, mainly in Goiás. The research had as theoretical orientation the materialism-historical-dialectic and the method used was the qualitative of the historical type. As instruments we consulted documents, bibliographical readings, testimonies, oral reports and interviews, as a way to obtain information and knowledge
\end{abstract}

\footnotetext{
* Mestra em Educação pela Universidade Federal de Goiás. Professora do Curso de Pedagogia do Centro Universitário de Mineiros-GO / UNIFIMES. E-mail: lucienecpereira@gmail.com.
} 
about the object under investigation. The research universe covered a total of 180 interviewees, of whom 97 were men and 83 were women aged between 61 and 103 years. We tried, through the reports and interviews of the elderly, to make a survey of the plays they experienced during their childhood and that remain in children's universe. Among the most cited are the nursery rhymes, little corral, wooden horse, hut and calf lacing. We also discuss some categories that emerged from the reports of the elderly, such as work, violence and gender.

Keywords: Childhood. Child's plays. Elderly. Memories.

Resumen: Este estudio "Una mirada a la infancia y los juegos para niños a partir de relatos de adultos mayores de la ciudad de Mineiros “, es el resultado del proceso de investigación desarrollado en el período que va de 2004 a 2007. El trabajo tuvo como objetivo conocer y comprender los juegos infantiles en la vida de las personas mayores de Mineiros entre las décadas de 1910 hasta 1940. Nos propusimos investigar cuál es el lugar del juego en la infancia de los mayores de Mineiros y, para ello, buscamos articular los elementos históricos constitutivos de la infancia, principalmente en Goiás. La investigación tuvo como orientación teórica el materialismo-histórico-dialéctico y el método utilizado fue el cualitativo de tipo histórico. Como instrumentos consultamos documentos, lecturas bibliográficas, declaraciones, historias orales y entrevistas, como manera de conseguir informaciones y conocimientos sobre el objeto investigado. El universo de la investigación abarcó un número de 180 encuestados, 97 hombres y 83 mujeres con edades desde 61 hasta 103 años. Buscamos, a través de los informes y entrevistas de las personas mayores, hacer un análisis de los juegos vivenciados por ellos durante su infancia y que permanecen en el universo infantil. Entre los más citados encontramos los juegos de rondas, de corralito, caballito, de casita y enlazando el ternero. También hablamos sobre algunas categorías que surgieron a partir de los relatos de las personas mayores como: trabajo, violencia y género.

Palabras clave: Infancia. Juegos infantiles. Adultos mayores. Memorias.

\section{Introdução}

Se o hoje não é o ontem

E nem o amanhã é o agora,

Será que algum dia volta

Pra ser de novo outra vez

$\mathrm{O}$ que um dia foi embora?

Brandão (2004: 4)

Foi pensando nos versos de Brandão é que buscamos, através dos relatos de idosos, compreender sobre a infância e suas brincadeiras vivenciadas nos períodos de 1910 a 1940. Mas, por que buscar nos relatos de idosos essa compreensão? O que tornaria tão particular a busca de tais elementos nas lembranças de idosos?

A opção pela busca de elementos de memória e história através de relatos orais de idosos constituiu uma especial alternativa para a obtenção de dados extraordinários, os quais, certamente, dificilmente poderiam ser percebidos em outras fontes.

As peculiaridades dos relatos orais de idosos expressam-se tanto pelo conteúdo quanto pela forma, como mostra Ecléa Bosi (1994):

Um mundo social que possui uma riqueza que não conhecemos pode chegar-nos pela memória dos velhos. Momento desse mundo perdido pode ser compreendido por quem não os viveu e até humanizar o presente. A conversa evocativa de um velho é sempre uma experiência profunda: repassada de nostalgia, revolta, resignação pelo desfiguramento das paisagens caras, pela desaparição de entes amados, é semelhante a uma obra de arte. (BOSI, 1994, p. 82) 
Eleger os relatos orais de idosos como um caminho para se reconstruir imagens de uma determinada época ou conhecimentos, no nosso caso sobre a infância e as brincadeiras de mineirenses nos anos de 1910 a 1940 , nos possibilitou lançar mão de um infindável acervo de conhecimentos, ainda que na memória de populares encontremos lacunas, contradições e oposições. A compreensão destes relatos contribuiu para o surgimento de novas perspectivas sobre a infância e as brincadeiras infantis.

Este estudo tem por objeto a infância e as brincadeiras infantis em Mineiros-GO nos anos de 1910 a 1940. Para isso se fez necessário entender como esta infância foi se materializando dentro do contexto histórico e quais as brincadeiras vivenciadas por estes idosos. Marx (1978, p. 17) afirma que "Os homens fazem sua própria história, mas não a fazem como querem; não a fazem sob circunstância de sua escolha e sim sob aquelas com que se defrontam diretamente, legadas e transmitidas pelo passado". Por isso, para se compreender a realidade é necessário compreender a história dessa realidade, porque a forma como ela tem se apresentado não nos ajuda a apreender suas dimensões. Prova disso é o que temos presenciado em relação à infância e às brincadeiras infantis em nosso meio.

Como parte integrante da cultura popular, as brincadeiras infantis, denominadas por Fernandes (2004) de folclore infantil, guardam segredos e revelam formas de vida muito interessantes dentro de uma sociedade. Esse tipo de cultura não é oficializado, mas vive na memória daqueles que um dia também foram crianças e das próprias crianças. Por isso, as brincadeiras não são algo estático, não se cristalizam, porque elas se desenvolvem também através da oralidade, passando de geração para geração de formas bem variadas, seja na escola, nos grupos religiosos, de amigos, vizinhos e parentes.
As brincadeiras infantis, neste sentido, também nos permitem conhecer as nossas origens, mas para conhecê-las é preciso que se busquem outras fontes que não sejam somente livros, pinturas e música. As memórias dos idosos, coletadas através dos relatos orais, muito contribuem para conhecer a infância e suas brincadeiras em tempos que não voltam mais.

\section{O contexto da pesquisa - mineiros: localização geográfica, histórico, população e aspectos socioculturais}

O Município de Mineiros, situado no Sudoeste de Goiás e com sede distanciada a 420 km de Goiânia, capital do Estado, é formado por um cenário de belas paisagens naturais, próprias do bioma "cerrado", com seus campos, veredas, matas ciliares, bacias sedimentares, rios e cachoeiras, que se contrapõem às plantações de soja, milho, cana-de-açúcar e à criação de gado e aves, especialmente perus.

Segundo dados do Instituto Brasileiro de Geografia e Estatística - IBGE (2008), Mineiros conta com uma população de 47.500 habitantes.

A história da fundação de Mineiros começa neste período, da transição do Império para a República, época em que a densidade populacional era muito baixa para as enormes extensões de terra existentes. O sudoeste de Goiás e, especialmente, a região divisória com a Bahia e o Mato Grosso Goiano apenas começavam a ser desbravadas. No sudoeste goiano, as terras alcançavam valor irrisório, sendo consideradas impróprias para o cultivo e apropriadas para a criação de gado. Assim, um número significativo de pessoas de Minas Gerais migrou para essa região, a fim de criar gado. Ali se estabeleceram com suas famílias à procura de melhores condições de vida. 
Esse processo, portanto, deve ser entendido à luz da história social dos homens e da necessidade de se manterem em condições de se constituírem como seres socioculturais autônomos, possuidores de bens de existência, assegurando condições materiais para a sobrevivência.

Podemos aqui lembrar o que já havia apontado Marx e Engels (1984: 31):

(...) da vida fazem parte, sobretudo comer e beber, habitação, vestuário e ainda algumas outras coisas. O primeiro ato histórico e, portanto a produção dos meios para a satisfação destas necessidades, a produção da própria vida material, e a verdade é que este é um ato histórico, uma condição fundamental de toda história que ainda hoje, tal como há milhares de anos, tem se ser realizado dia a dia, hora a hora, para ao menos manter os homens vivos.

Na realidade, o homem sempre agiu sobre a natureza para atender às suas necessidades e, por mais que a coloque sob o seu controle, sempre permanecerá no reino da necessidade. Foi o que aconteceu com os migrantes que fundaram a cidade; à medida que o espaço onde se encontravam não satisfazia mais seus interesses, saíram à procura de novos lugares para se estabelecerem.

\section{Brincando na Cidade de Mineiros em Goiás nas Décadas de 1910 a 1940}

No Brasil, como em qualquer outro lugar, as brincadeiras se fazem presentes na vida das crianças, de maneira geral, embora se apresentem diferenças socioculturais. $\mathrm{O}$ brincar tem uma dinâmica que não o deixa tornar-se estático, por isso podemos perceber as mudanças e permanências das brincadeiras ao longo do tempo. Muitas delas foram incorporadas e adaptadas de um lugar para outro por novos olhares e novas gerações. Em cada período ou época essas manifestações marcam a cultura de um povo e se apresentam de maneiras diferentes, permeadas de ludicidade, moralismo, violência e mesmo de preconceitos étnicos e de gênero.

Diante disso, podemos perguntar: Como a criança adentra no mundo da cultura em que as manifestações folclóricas se fazem presentes?

Na percepção de Vigotski (2004), a entrada da criança nesse mundo cultural se dá através da atividade e da adaptação ativa. Para Leontiev (2004), ela ocorre por meio dos processos de adaptação e apropriação da cultura. Essa apropriação e adaptação de que tratam os autores deve ser compreendida como algo em movimento; a cultura percebida dentro desse contexto é movimento e como tal se encontra em constante embate com a tradição que possui uma conotação de estabilidade e continuidade. A mobilidade da cultura e sua construção ocorrem dentro da história, que também não é algo estático no tempo e no espaço, porque está em constante renovação. A tradição faz o movimento contrário, uma vez que se consolida e se conserva. No embate entre renovação e conservação é que podemos compreender a cultura como hábitos, atitudes, maneiras de lidar e de representar a realidade que nos cerca.

As realidades advindas da cultura são próprias do homem, cujo comportamento é influenciado social e historicamente. Luria (1979) demonstra de forma enfática como esse processo de assimilação dos elementos culturais é retido pela criança:

Desde o momento em que nasce, a criança forma o seu comportamento sob a influência das coisas que se formaram na história: senta-se à mesa, come com a colher, bebe em xícara e mais tarde corta o pão com a faca. Ele assimila aquelas habilidades que 
foram criadas pela história social ao longo de milênios. (...) A grande maioria de conhecimentos, habilidades e procedimentos de comportamento de que dispõe o homem não são resultados de sua experiência própria, mas adquiridos pela assimilação da experiência histórico-social de gerações. (LURIA, 1979, p. 73)

A criança incorpora/apropria-se de experiências histórico-sociais de seus antepassados e por isso Luria (1979), nos permite pensar na existência de elementos de conservação dentro da cultura. Desse modo, a forma como o homem age nesse mundo material permanece de geração para geração. Não se trata de um processo passivo de assimilação diante da realidade, pois nesse processo há uma recriação e ressignificação do mundo real, consequente da relação dialética que o homem mantém com o mundo, seja de maneira natural ou social.

Barbosa (1997, p. 29), seguindo essa visão dialética marxiana, afirma que “ao transformar o mundo e ser transformado por ele, o homem é também capaz de promover a autotransformação”. Torna-se, assim, ininterrupto esse processo de produzir, transmitir, transformar, recriar e conservar a cultura.

Com isso, podemos dizer que as brincadeiras, a que chamamos de folclore, por se tratarem de manifestações culturais, se inserem neste contexto. Segundo Fernandes (2004), o folclore é uma ciência popular e a sua transmissão ocorre, principalmente, através de processos informais, nos quais o intercâmbio entre as pessoas vai acontecendo, no dia a dia, das mais variadas formas, seja na escola, no bairro, no grupo religioso, no clube ou entre parentes. A condição para que o folclore exista e resista, ou seja, para que ele se manifeste, é a aceitação por parte da comunidade que o cultiva.
Por cultura infantil se entende, segundo Fernandes (2004), o mesmo que folclore infantil, só que o autor estabelece uma diferença, mostrando que a cultura infantil,

abrange alguns elementos ou complexos culturais de natureza não folclórica, como futebol ou a natação (...) e certos trabalhos caseiros (confecção de roupinhas para as bonecas, preparação de doces simples, que as crianças aprendem a fazer com maior rapidez. (p. 214)

Em nossa pesquisa, estes elementos elucidados por Fernandes (2004) se fizeram presentes nos relatos dos idosos quando disseram que brincavam de fazer comidinha, de comadre, de futebol e de banhar no rio. Por isso, compreendemos as brincadeiras tradicionais vivenciadas pelos idosos não apenas como folclore, mas como parte integrante da cultura infantil. Elkonin (1998) atesta que as crianças têm necessidade de compreender esses papéis sociais em que os adultos estão inseridos.

$\mathrm{Na}$ pesquisa que realizamos com os idosos de Mineiros, nascidos entre 1910 e 1940, foram levantadas questões com o intuito de verificar quais eram as brincadeiras que faziam parte da sua infância, bem como as mudanças e permanências de determinadas brincadeiras. Para compreendermos qual o papel que estas brincadeiras exerciam em suas vidas, não era possível voltarmos aos 180 entrevistados, por isso refizemos algumas entrevistas, perfazendo um total de 20 idosos entrevistados. Durante a década de 1910, as brincadeiras lembradas por nossos entrevistados estavam muito ligadas à própria condição em que viviam. Nessa época, a população do município de Mineiros, em sua maior parte, encontrava-se na zona rural ${ }^{1}$ e, por consequência, predominavam entre as

${ }^{1}$ O IBGE não realizou o censo nesta época. 
crianças os tipos de brincadeiras relacionados diretamente ao ambiente rural.

As brincadeiras das crianças representavam o cotidiano vivido pelos adultos em suas atividades de trabalho, tais como cavalinho de pau, boi de barro, laçar bezerro, casinha, entre outras.

Além destas brincadeiras, outras também foram citadas pelos nossos entrevistados, não como brincadeiras prediletas, mas que faziam parte do seu cotidiano infantil, como balanço, baliza, cobra-cega, curralzinho, carrinho de buriti, passar anel, peteca e soltar pipa.

Segundo Kishimoto (1993), tais brincadeiras eram percebidas em muitas regiões brasileiras, porque a influência das culturas negra, indígena e portuguesa se fizeram presentes no setor econômico, cultural e social em nosso País. É interessante ressaltar que essa influência pode ser vista nos brinquedos inventados pelas próprias crianças, que se utilizavam de elementos da natureza para fabricar seus próprios brinquedos, tais como: o carrinho de talo de buriti, boizinhos de osso de suã e petecas de palhas de milho e penas de galinha.

Já década de 1920 as brincadeiras prediletas eram: carrinho de boi, gangorra, subir em árvores, curralzinho, esconde-esconde, peteca, casinha, boneca de pano, comidinha, roda, cavalinho de pau, boneca

Muitas das brincadeiras prediletas permanecem entre as crianças mineirenses, com exceção daquelas que se perderam no tempo, como as do boi de sabugo, do carrinho de cabaça, de amarrar capim no "trieiro" e da rolinha rolou. O banho no rio é uma das brincadeiras que permanecem, porque, pelo fato da região situar-se num divisor de águas, é muito raro uma fazenda não ter um rio, um riacho, um ribeirão ou um córrego com um "poço fundo para banhar”. Segundo
Kishimoto (1993), as brincadeiras nos rios são costumes das crianças indígenas que imitavam os adultos e que foram transmitidos aos portugueses.

Na década de 1930 as brincadeiras desta época permaneciam com seus contornos rurais e aconteciam principalmente nos finais da tarde, nas noites de lua cheia e nos finais de semana, dentre ela podemos citar: montar bezerro, boneca de pano, carrinho de sabuco, brincar de roda, peteca, casinha, futebol, comidinha, esconde-esconde, boi de sabugo, boneca, cavalinho de pau.

Muitas brincadeiras que não foram consideradas por nossos entrevistados como prediletas também faziam parte do cotidiano infantil. Dentre elas destacamos andar a cavalo, briga de galo, baliza, basquete, sacarrilha, bodoque, brincar com calango, caçar passarinho, lutinha, matinê dançante, pular corda, pular elástico e queima. Quando se reuniam as meninas e os meninos para brincar, geralmente brincavam mais de cobra-cega, esconde-esconde, perna de pau, peteca, pular corda e pular barranco para cair na água, algo permitido por seus pais, porque tinham medo que os meninos tomassem gosto pelas brincadeiras de meninas.

Em 1940 a brincadeiras prediletas eram: boi de sabugo, carrinho de sabugo, perna de pau, estilingue, montar bezerro, balanço, correr, futebol, pular corda, bolita, nadar no córrego, barra manteiga, cabra-cega, pião, pique esconde, passar anel, queima, boneca de sabugo e de pano, subir em árvores, cavalo de pau, bola, esconde-esconde, roda, pipa, roubar bandeira, jogo de botões, casinha e comidinha,

Das brincadeiras prediletas citadas, podemos dizer que laçar e montar bezerro, queima, peteca, futebol, empinar pipa, roda, cavalinho de pau, casinha, comidinha, roubar bandeira e jogo de botões continuam presentes 
na cultura infantil. A grande mudança que se deu é que as crianças já não constroem os bois de sabugo, as bonecas de espiga de milho e o pião. Estes brinquedos foram industrializados, ganharam formas diversificadas em sua composição e ainda continuam encantando as crianças.

\section{Idosos e crianças: extremos?}

Ao reconstruirmos a infância através dos diálogos com idosos na cidade de Mineiros-GO, pudemos compreender como essa infância se constituiu enquanto categoria na sociedade. Os relatos evidenciaram que a infância nem sempre foi marcada pela alegria, mas que a dor, o preconceito e a desilusão caminharam lado a lado com muitos idosos durante sua infância, principalmente junto àqueles que não detinham o poder econômico. Apesar disso, a possibilidade de se ter alguém com quem compartilhar as lembranças da infância pareceu representar um momento especial para os idosos que entrevistamos. Percebemos isso durante nossa entrevista com o Sr. A (103) que, ao nos despedirmos, ressaltou: "Faz sempre assim, venha conversar comigo, gosto muito de conversar e tocar música” (Entrevista em: 30/11/2006).

Apesar do apoio da família, de morar com a filha e o genro, que são detentores de boa condição econômica, o Sr. A (103) sente necessidade de conversar, gosta de estar no meio dos jovens. Afirma ainda que não se sente velho e que sua jovialidade tem a ver com a música, inclusive fez questão de dizer que toca qualquer instrumento musical e que já compôs várias músicas para suas netas e bisnetas, mas que as pessoas quase não têm mais tempo para conversar e ouvir suas músicas, pois é um “corre-corre danado!”, diz ele.

O Sr. A (103) expressa uma angústia vivida por pessoas de outro tempo, um tempo em que ele trabalhava e brincava em seu fazer de criança, um tempo em que na juventude se fazia serenatas, conversava com os amigos, mas que agora na velhice é escasso. O Sr. A (103) expressa o impacto causado por um tempo que é comandado pelo capital, em que as transformações econômicas, sociais, científicas e culturais têm se refletido cada vez mais nas relações que o homem estabelece com o outro. É a mercantilização que torna as pessoas mais distantes porque precisam empregar o seu tempo na satisfação das necessidades reais e ou criadas pelo sistema capitalista, como afirma Marx (apud MANACORDA, 1991).

A fala do Sr. A (103) denuncia ainda que a sociedade somente considera o homem enquanto é produtivo, depois é descartado como uma coisa ou objeto qualquer. A desvalorização do idoso é uma herança da Idade Moderna, mais especificamente no século XIII. Com a transição do modo de produção feudal para o capitalismo, o velho passa a ser desnecessário para a família burguesa, por não produzir mais como antes. Marx (1984) afirma que quando o mundo das coisas passa a ser mais valorizado, o homem perde o seu valor e torna-se um estranho até para si mesmo.

Na sociedade capitalista, tudo se torna efêmero: a cultura, os costumes, os valores morais e éticos, e não há uma preocupação em preservar a memória. Os guardiões da memória são entregues à casa de repouso e muitas vezes a família, em nome do bem-estar, passa a administrar sua aposentadoria como se fossem incapazes de gerenciar seus gastos. Nesta fase da vida, muitos idosos são obrigados a sair de suas casas para viver em ambientes estranhos a eles, não se perguntando nem se discutindo o que eles querem; seus conselhos e experiências já são considerados ultrapassados. Esta é uma sociedade maléfica para com a velhice. 
O velho sente-se um indivíduo diminuído, que luta para continuar sendo homem. O coeficiente de adversidade das coisas cresce: as escadas ficam mais duras de subir, as distâncias mais longas a percorrer, as ruas mais perigosas para atravessar, os pacotes mais pesados para carregar. $\mathrm{O}$ mundo fica eriçado de ameaças, de ciladas. Uma falha e uma pequena distração são severamente castigadas (BOSI, 1994, p. 79).

Para o idoso, o mundo que antes parecia tão íntimo, agora se torna algo perigoso, distante, porque sua visão já não corresponde ao que era, a audição lhe parece diminuir, as pernas não possuem a agilidade de outrora, fica com medo de cair, sente dificuldade em andar e sentar. Para se locomover, ouvir e enxergar é necessário usar de artefatos: óculos, lupa, aparelho auditivo, bengala, andador. Sua autoestima fica comprometida diante de tantos empecilhos, por isso sentem-se incapazes.

Ao pedirmos que os idosos pesquisados, residentes em um dos abrigos de Mineiros falassem sobre sua infância e das brincadeiras que praticavam quando criança, ouvimos respostas como:

Quem sou eu para dar entrevista, já estou velho demais!” (Sr. M (78) entrevista em: 08/02/2007).

Será que vou saber responder direito?” ( $\mathrm{Sr}$. N (95) entrevista em: 08/02/2007).

Ah! Num lembro de mais nada, já estou caduco (risos)” ( Sr. O (78) entrevista em: 08/02/2007).

Por que a recusa em falar sobre suas memórias? Suas falas nos indicam que eles não se sentem importantes, talvez porque a sociedade tacitamente vai utilizando mecanismos que evidenciam a recusa em estabelecer diálogo com eles, demonstrando intolerância e desrespeito por meio das próprias instituições e serviços sociais.
A morosidade quanto ao atendimento das questões de ordem jurídica, como a dificuldade para se aposentar ou para conseguir remédios, são exemplos que demonstram a falta de preocupação com os direitos dos idosos. As instituições públicas e conveniadas de Mineiros a eles destinadas demonstram o descaso com o qual são tratados. As paredes descascadas e as calçadas quebradas retratam o precário estado físico dos prédios. As mobílias velhas e estragadas, os colchões inadequados para uso, as roupas de cama e banho surradas explicitam a falta de recursos para a manutenção das instituições. O reduzido número de funcionários para limpar o ambiente e cuidar da higienização pessoal dos idosos e a falta de materiais de limpeza e de uso pessoal acarretam um odor desagradável que incomoda os possíveis visitantes que, esporadicamente, aparecem para fazer a caridade de levar algo para alimentá-los.

Essa questão pode ser percebida em nosso diálogo com Sr. O (78). Ao perguntarmos sobre o que ele mais sentia falta, nos confidenciou:

Sr. O (78) - De tudo, de conversá, dos fios, de carinho de muié (risos). (...) "Depois que fiquei viúvo meus filhos venderam o que eu tinha, e me pois aqui, mais tá bão, pelo menos aqui eu num passo necessidade, mais que é ruim é”. (entrevista em: 08/02/2007)

Bosi (1994, p. 77) expõe que, para reverter esta situação a que os velhos estão imersos e conseguir um espaço dentro da sociedade do capital, é necessário acabar com os abrigos/asilos e, em seus lugares, construir espaços mais dignos, com profissionais adequados, que não fiquem preocupados com cuidados geriátricos, mas que ofereçam atividades que os façam se sentir úteis e "ofereçam sobrevivência à sua obra”. 
Thompson (1992), baseado nos estudos do psiquiatra norte-americano Bartlet, enfatiza a importância de se trabalhar com a reminiscência dos idosos através de grupos de discussão, porque essa seria uma forma de eles estarem reavaliando seus conflitos no passado e, consequentemente, se autoajudando, porque nesta fase da vida os idosos acabam sentindo-se inúteis, incapazes, desconfiando da sua própria condição humana. A reação do Sr. $\mathrm{O}$ (78), que sofre com as reminiscências do passado, chegando a se negar a falar delas, poderia ser trabalhada com atividades como as sugeridas por Thompson, que contribuiriam para amenizar a solidão em que se encontram diversos idosos. Porém, essa não seria a solução, pois os problemas são bem mais complexos. Estes não passam só pelo campo da subjetividade, afinal vivemos em uma sociedade cheia de contradições.

Marilena Chauí, prefaciando Bosi (1994, p. 18), faz um questionamento muito interessante quando diz: “Que é, pois, ser velho na sociedade capitalista? É sobreviver. Sem projeto, impedido de lembrar e de ensinar, sofrendo as adversidades de um corpo que se desagrega”. Estas questões nos ajudam a sinalizar o porquê da recusa em falar de suas memórias. Esta recusa foi precedida pelo descaso, pela desvalorização, e isso nos remete a outro tempo também vivido pelos idosos quando em sua infância também lhes era negado o direito à fala.

Se à criança a fala é negada pela sua desarticulação, o mesmo ocorre com o idoso, devido à desarticulação com o pensamento, como indica Ariès (1981: 07): “a velhice é assim chamada porque as pessoas velhas já não têm os sentidos tão bons como já tiveram e caducam em sua velhice”. Ambos, as crianças e os idosos, não são reconhecidos em suas especificidades. A criança é também entendida como aquela que é desprovida de conhecimentos, cuja fala não tem valor. $\mathrm{O}$ mesmo ocorre com o idoso que, mesmo tendo o conhecimento decorrente dos anos de vida, é compreendido como alguém fora do tempo.

Outra aproximação existente entre o infante e o idoso é com relação aos cuidados que exigem. Há idosos que necessitam que lhes seja dispensado vários tipos de cuidados, como o de higiene, administração de medicamentos e de alimentos, tendo que se submeter a quem possa fazê-lo, mesmo ocorrendo com a criança. Como afirma Charlot (1986, p. 106), “a impotência da criança não se caracteriza pela impossibilidade de satisfazer sua fome encontrando, ela própria, os alimentos de que precisa, mas pela necessidade, na qual se encontra, de se dirigir aos adultos que lhe fornecem os alimentos que lhe são indispensáveis”.

A criança e o idoso precisam do apoio do outro para a sua sobrevivência. Essa dependência é entendida como falta de capacidade e é generalizada para outras atividades que podem realizar. Assim, em muitos casos, principalmente nas instituições, a eles são negados o direito à fala, não sendo reconhecidas as suas capacidades cognitivas e necessidades afetivas.

\section{Memória e tradição: diálogos sobre a infância}

Os idosos, dentro do contexto familiar, são os guardiões da memória, os elos entre o passado e o futuro, os mediadores entre uma geração e outra. Segundo Barros (1989: 33): “A figura dos mediadores ganha uma função fundamental nesse processo de manutenção da identidade grupal. Apresentados como elo vivo entre as gerações, os mediadores transmitem a história de um passado vivido e experimentado”. Um exemplo de transmissão do passado feito pelos guardiões da memória pode ser visto na entrevista com a Sra. D (90), 
quando fala sobre a "traição"2 que acontecia em seus tempos de criança e que permanece até hoje. Ao relembrar sua infância, Sra. D (90) relatou que sua família:

(...) dava muita traição e nessa traição trabalhava bastante e de noite dançava bastante, até o sol alto e até hoje nois fais isso. (...) tinha pinguinha, dançava, tocava a noite inteira, as veis um tocava e o outro ia dançá [...] via minino abraçado com minina ançano do mesmo jeito (risos) desde pequeno dançava era de tudo e nóis fais isso até hoje. (Sra. D (90), entrevista em: 29/01/2007).

Outro exemplo sobre costumes que se tornaram tradição é possível ser visto no relato da Sra. W (84): "No começo as mães fazia as boneca, depois nois mesmo (...) foi com a minha mãe que aprendi a faze essas boneca que faço e vendo aqui” (Sra. W (84), 14/01/ 2007).

As lembranças da Sra. D (90) e da Sra W (84) as acompanham até hoje. Isso nos remete às palavras de Bosi (1994), que expõe que:

Ao lembrar o passado ele não está descansando, por um instante, das lides cotidianas, não está se entregando fugitivamente às delícias do sonho: ele está se ocupando conscientemente e atentamente do próprio passado, da substância mesma da sua vida. (p.60)

Ao se ocupar de forma consciente e atenta ao passado, o idoso não está divagando e nem sonhando, ele está refazendo,

\footnotetext{
${ }^{2}$ É a tradição de os vizinhos de fazenda se juntarem para ajudar um outro que precisa dar conta de uma tarefa em suas terras (limpar o terreno para plantar, fazer o plantio, arrumar a cerca, o curral, dentre outros). Enquanto os homens fazem o serviço no campo, as mulheres fazem a refeição para todos e à noite acontece o baile de despedida e agradecimento.
}

reconstruindo o caminho com as ideias de hoje, mas com um pé ancorado nas experiências vividas no passado. Para reconstruir o passado, ele busca outras fontes, como os amigos, os álbuns de família, os bilhetes, as cartas, tudo que possa servir de referência para que as lembranças sejam precisas, não só a busca em suas memórias e nos artefatos, como continua a fazer as coisas que no passado foram importantes, só que de maneira diferente dentro de um outro contexto, objetivando preservar as tradições.

Como aponta Hobsbawn (2006: 14), "as práticas tradicionais existentes - canções folclóricas, foram modificadas, ritualizadas e institucionalizadas para servir a novos propósitos nacionais”. Da mesma forma, as atividades lembradas pela Sra. D (90) e Sra. W (84) que fazem parte das tradições do povo mineirense também foram preservadas e modificadas para ser utilizadas em outros contextos. A “traição” tem sido utilizada por homens do governo com o propósito de construir moradias, sendo essa prática modificada no que concerne ao grupo atendido; não é mais o vizinho amigo, como era feito anteriormente, mas o eleitor cujo voto se pretende conquistar. Também o feitio da boneca de pano que tinha como finalidade entreter a criança que não detinha poder econômico para comprar as tão raras bonecas de porcelana, hoje tem modificado o objetivo de seu feitio. Elas têm sido vendidas em feiras de artesanato para fazer parte de coleções. Isso não significa que em seu contexto de origem essas tradições não tenham sido preservadas sem modificações, ou seja, no campo, continuam sendo realizadas as “traições” entre amigos e vizinhos, e as bonecas de pano ainda são feitas para as crianças brincarem. Mesmo com essas modificações, as lembranças dos idosos ficaram retidas nos costumes do tempo de sua infância e juventude, com saudades de um tempo que passou. 
Por isso, afirmamos que o idoso se preocupa mais com o passado do que qualquer um, como nos ensina Bosi (1994). Ele olha para o passado para compreender o hoje, precisa refazer o caminho, uma questão de sobrevivência. Portanto, a memória é uma forma de trabalho, sério e árduo, como afirma Halbwachs (2004); não é diversão, é um voltar-se a si mesmo, uma espécie de obrigação em desvelar o mundo real.

Vigotski (1998b, p. 39) coloca que “a memória é extraordinariamente forte na infância e que com o desenvolvimento da criança vai se debilitando cada vez mais”. Mas esta debilitação não significa que a criança ao se tornar adulta não se lembre mais das coisas porque "a verdadeira essência da memória humana está no fato de os seres humanos serem capazes de lembrar ativamente com ajuda de signos” (VIGOTSKI, 1998a: 68).

A exemplo, temos os relatos dos idosos sobre o que brincavam durante a infância. Suas lembranças foram possíveis de serem reativadas porque foram mediadas por signos. Ao buscarem em suas memórias não lembraram de forma aleatória, pois há toda uma significação, um contexto social, econômico e político que ajuda nesse processo de rememoração.

Os signos e seus significados socioculturais são, portanto, fundamentais na constituição da história individual e coletiva, seus costumes, seus processos e tradições. $\mathrm{O}$ que diferencia costume de tradição é exatamente a ação. Enquanto a tradição é uma prática fixa, o costume não impede as inovações e as mudanças.

Ao procurarmos estabelecer diálogo com os idosos, suas memórias trouxeram à tona muitos costumes que hoje não se usam mais, mas que permanecem em suas lembranças. Trouxeram também o valor e a força das tradições que, para eles, têm um significado maior do que para os jovens, embora estes continuem a utilizá-las. Ao analisarmos as entrevistas que fizemos com os idosos, percebemos que algumas informações tornaram-se comuns, como a ênfase do trabalho na infância, a violência com que eram tratados e a distinção de comportamento conforme o gênero. Assim, o trabalho, a violência e o gênero constituíram-se como categorias para a análise sobre a infância e as brincadeiras dos idosos de Mineiros, considerando-se suas memórias e tradições.

\section{Considerações finais}

As situações as quais nos referimos foram evidenciadas em nosso trabalho de pesquisa, que teve como objetivo conhecer e compreender as brincadeiras infantis através dos relatos de idosos. As pesquisas e os relatos possibilitou-nos compreender que não era possível extrair uma recordação pura e intacta, tal como se deu no momento do acontecimento porque, ao rememorar suas lembranças, os idosos não o fazem fora do contexto em que estão inseridos.

Sentimos que em cada entrevistado ou entrevistada havia uma satisfação enorme em relatar o passado. É como se o mundo estivesse com as atenções voltadas totalmente para eles, e a oportunidade de falarem de algo que só eles vivenciaram ou de ensinar os mais jovens sobre um tempo que não viveram ficou evidenciada na seriedade com que nos iam transmitindo as informações.

Mas também presenciamos, durante as entrevistas, muita tristeza, como por exemplo quando fomos entrevistar os idosos do Abrigo Bom Pastor, ${ }^{3}$ onde nos deparamos com uma realidade típica da sociedade do capital: o

\footnotetext{
${ }^{3}$ Este abrigo foi construído na segunda metade da década de 1960 pelas Obras Sociais da Paróquia do Divino Espírito Santo - OSPDES, que o mantém.
} 
desrespeito com os mais velhos, o abandono, a falta de compreensão, de paciência e de carinho por parte dos parentes, que não aparecem lá para visitá-los. Ali, as únicas pessoas com as quais podem contar são os funcionários do abrigo.

É interessante ressaltar que, ao ouvirmos os idosos sobre a infância e suas brincadeiras, observamos que os lapsos de memória que hora ou outra ocorriam nos relatos faziam parte do processo de recordar, que a memória não se apresentava de forma linear, uma vez que uma palavra podia provocar determinadas recordações. Recordações estas que eram permeadas de tristezas ao rememorar o sabugo de milho que fora esfregado em seu rosto por não ter lavado a roupa direito, mas também havia contentamento em lembrar um período em que não tinham muito com o que se preocupar na vida.

Ao procedermos à pesquisa bibliográfica e empírica, percebemos o quanto a etimologia da palavra brincadeira e seu significado carregam uma carga semântica como "coisa de pouca importância”, “diversão”. Essa é a concepção que os relatos dos idosos deixaram transparecer. Quando abordamos os idosos se era importante a criança brincar, eles nos disseram que sim, porque brincar é diversão, e passatempo é não ter responsabilidade. Para a abordagem histórico-cultural, a brincadeira não é só alegria, divertimento, mas também é um momento de desprazer porque, quando a criança brinca, os conflitos cotidianos vão sendo evidenciados. Ao brincar, as crianças se tornam narradoras de sua própria história, da história do grupo, da história de sua comunidade. Porque a brincadeira é a primeira forma de comportamento consciente da criança, permitindo-lhe construir novos caminhos e novas possibilidades para que a criança possa agir sobre o meio e fazer novos arranjos.
Os dados de nossa investigação nos revelaram a influência socioeconômica cultural nas brincadeiras infantis. Segundo Marx (1978), não se pode compreender a vida social fora do processo econômico e como essa sociedade capitalista se organiza. As brincadeiras evidenciadas nas décadas de 1910 a 1940 demonstraram que o ambiente em que eles estavam inseridos, o contexto rural durante a infância, influenciou as brincadeiras e os brinquedos. É por isso que o cavalinho de pau, boi de sabugo, laçar bezerro, montar cavalo, balanço, a casinha, brincadeira de roda, peteca, boneca de pano, subir em árvore, o banho no rio, curralzinho, pular barranco, esconde-esconde, caçar passarinho, futebol, a comidinha, empinar papagaio, ouvir histórias, urticã (queima), ordem e tantas outras brincadeiras não poderiam ser diferentes. Essas brincadeiras mostram a realidade vivida pelos idosos durante a infância.

\section{Referências}

ALTMAN, R. Z. Brincando na história. In.: DEL PRIORE, M. (Org.) História das crianças no Brasil. 3. ed. São Paulo/SP: Contexto, 2002, p. 231-258.

ARIÈS, P. História social da criança e da família. 2. ed. São Paulo: LTC, 1981.

BARBOSA, I. G. Pré-escola e formação de conceitos: uma versão sócio-históricodialética. 1997. 169 fls. Tese (Doutorado em Educação) - Universidade de São Paulo, São Paulo.

BOSI, E. Memória e sociedade: lembranças de velhos. São Paulo/SP: Companhia das Letras, 1994.

BARROS, M. L. Memória e família: estudos históricos 1989/3. Rio de Janeiro/ RJ, 1989. 
BRANDÃO, C. R.O jardim de todos. Campinas: Autores Associados, 2004.

CHARLOT, B. A mistificação pedagógica: realidades sociais e processos ideológicos na teoria da educação. 2. ed. Rio de Janeiro/RJ: Guanabara, 1986.

ELKONIN, D. B. Psicologia do jogo. Trad. Álvaro Cabral. São Paulo: Martins Fontes, 1998.

HALBWACHS, M. A memória coletiva. Trad. Laís Teles Benoir. São Paulo/SP: Centauro, 2004.

KISHIMOTO, T. M. Jogos infantis: o jogo, a criança e a educação. Petrópolis: Vozes, 1993.

LEONTIEV, A. O desenvolvimento do psiquismo. São Paulo: Centauro, 2004.

LURIA, A. R. Curso de psicologia geral. Rio de Janeiro: Civilização Brasileira, 1979.

MANACORDA, M. A. Marx e a pedagogia moderna. São Paulo: Cortez: Autores Associados, 1991.

MARX, K. O 18 Brumário e as cartas a Kugelmann. Rio de Janeiro: Paz e Terra, 1978.

ENGELS, F. A ideologia alemã: teses sobre Feuerbach. São Paulo: Centauro Editora, 1984.

THOMPSON, P. A voz do passado: história oral. Rio de Janeiro: Paz e Terra, 1992.

VIGOTSKI, L. S. Psicologia pedagógica. 2. ed. São Paulo: Martins Fontes, 2004.

VIGOTSKI, L. S. A formação social da mente: o desenvolvimento dos processos psicológicos superiores. 6. ed. São Paulo: Martins Fontes, 1998a.
L. S. O desenvolvimento psicológico na infância. São Paulo: Martins Fontes, 1998b. 